\title{
INTEGRATING NETWORK CONCEPT INTO MULTI CRITERIA ANALYSIS FOR SUGGESTING BUS RAPID TRANSIT ROUTES
}

\author{
Nur Liyana Binti Jamalul Shamsudin ${ }^{1}$, Mohd Faisal Bin Abdul Khanan ${ }^{1}$, Hafiz Aminu Umar ${ }^{1}$, Siti Nurulainni Binti Atan ${ }^{2}$, Ami \\ Hassan Md Din ${ }^{1}$ \\ ${ }^{1}$ Department Geoinformation, Faculty of Built Environment and Surveying, Universiti Teknologi Malaysia, 81310, Johor Bahru, \\ Malaysia- N.L.J.S- nurliyanajs@ gmail.com, M.F.A.K.- mdfaisal@utm.my, H.A.U.- abdulhafizamin@yahoo.com, A.H.M.D.- \\ amihassan@utm.my \\ ${ }^{2}$ Iskandar Regional Development Authority (IRDA), 80200, Johor Bahru - S.N.A.- nurulainni@irda.com.my
}

KEY WORDS: BRT, Multi Criteria Analysis, Network Analysis, Analytical Hierarchy Process, Route Suggestion.

\begin{abstract}
:
Population explosion in the city of Johor Bahru has led to traffic congestions, which hitherto to that there were better movements and flow of vehicles in and around the city. Road transportation in particular has played a gargantuan role in creating and maintaining easy and quick access to various destinations. Increases in the number of vehicle indicate a higher economic prosperity that contributes to traffic congestion within the city. This can be seen in a number of developments such as increased population density and creation of alternative routes over several years, which has still not totally eradicated the traffic congestion problems of the city. Ideally, a good public transport service would carry the passenger directly from their origin to their destination without having to face traffic congestion. The buses may not be available and accessible from certain origins or destinations of residents or they may need to walk some distances from their residents to the bus stops resulting into discouragement for most of the people using public transport services. This paper aims to utilise geospatial analysis approach to suggest effective bus routing that would be able to increase connectivity to rural areas and boost commercial activities through better transportation. Route selection is the process of finding locations that meet the selection criteria for each parameter using Geographic Information System (GIS). The process employs applied multi-criteria decision analysis and network analysis to generate thpsye highest score areas for bus rapid transit (BRT) route by maximising network and mobility and ensuring the newly suggested routes are connected to the existing networks of BRT to serve the community.
\end{abstract}

\section{INTRODUCTION}

Public transportation has played a major role in decongesting most of the roads worldwide and due to it is utmost importance many countries around the world have dedicated bus lanes that are not shared with other public transports like taxis, motorcyclist and cyclists. In Malaysia, buses are among the common form of public transport that operated by both public and private transportation companies, conveying commuters from one destination to the other at affordable price. One advantage of public transportation in Malaysia is the provision of modern parking lots that provides an opportunity for both commuters and buses drivers to take a short break while driving on a long journey, especially interstate buses.

However, in Petaling Jaya, a suburb of Selangor Malaysia, BRT has dominated the public transportation sector due to it is efficiency and easy access to the road networks within the metropolis. This is attributed to the fact that BRT has it is own personal lane that commutes passengers in an around the city in a hitch free atmosphere without encountering traffic congestions.

Bus rapid transit system began in the Brazilian city of Curitiba around 1974 with the motive of improving public transportation system that would guarantee full customer satisfaction. However, there was an attempt by other transport sectors to developed alternative transportation system that would serves the purpose at a smaller scale (Wright, L ,2005). United States of America around 1960s was the first nation to construct a dedicated busy lane and subsequently about $7.2 \mathrm{~km}$ was constructed in Lima by the government of Peru popularly known as "Via Expresa". One year later busy lanes were constructed in Runcorn (United Kingdom) and Los Angeles (USA). Wright, L. (2005) has also identified back in the days, when bus rapid transit (BRT) was not commissioned, London's bus network serves 5.4 million passengers each day, far exceeding the city's underground metro system. To achieve its level of performance, the London bus system makes extensive use of bus lanes. However, bus lanes are significantly different in nature to the busways found in most BRT systems.

BRT in Malaysia was first lunch in the south eastern suburb of petaling jaya, Selangor around June 2015 and since then, the company has rolled out many blueprints to expand it is operation to many cities in Malaysia. It is part of the government efforts to improve urban public transport system due to the growing population in most cities and town in the country.

The growing population in and around the city of Johor Bahru has led to traffic congestion and it seems surprisingly high, affecting the free movements of vehicles especially during the working hours and festive periods (Steve Meyrick, 2006). As Johor Bahru is keen to adapt Bus rapid system (BRT) as an alternative public transportation system, it will undoubtedly bring the much needed relieves to many passengers that moves around the cities and villages.

This study therefore, utilized geospatial analysis approach to suggest effective bus routing that is capable of increasing connectivity between urban and rural areas and that would boost commercial activities for better transportation. In order to achieve the aim, the objectives are listed below: 
- To identify the current practices of bus routing in Iskandar Malaysia, Johor Bahru.

- To conduct multi-criteria evaluation method using GIS for the crucial decision making to allocate the best bus rapid transit (BRT) route.

- $\quad$ To improve the route mapping for bus rapid transit (BRT).

\section{METHODOLOGY}

Multi criteria decision analysis and network analysis of Geographic information system can be applied in structuring bus rapid transit (BRT) routes in Johor Bahru. This has become necessary due to the rising population density and land use development in and around the city. Statistics has shown that about 140,000 commuters patronised Bas Iskandar Malaysia on monthly basis, while Bas Ekspress Transit (BeXTRA) recorded and average of 219,446 passengers per month (IRDA, 2013).

Multi criteria Multi criteria decision analysis can be applied successfully to identify the optimum BRT routes from point of departure to various destinations. The optimum BRT routes are easily accessed routes, has the least development cost and satisfies other environmental, social and economic criteria (Lutz, 2014). Figure 1 shows the methodology that will be implemented in order to achieve the aim and objectives of this research.

\subsection{Preliminary Study}

The rationale behind the application of multi criteria decision analysis is to develop an idea on how bus routing can be applied in solving public transportation system and to have an in-depth understanding of BRT standards so as to drives the much needed parameters that would be use in performing multi criteria decision analysis. It is imperative to do parameterization based on previous literature of rapid transit. Furthermore, the agencies involve in BRT implementations should be fully involve in considering the appropriate bus routing points and the criteria for routing selections.

The NKRA identified that $63 \%$ of the population lived within 400 meters of a bus service. Roberts (2010) has listed the major criteria to consider in bus route selection:

- Location of origins, destinations and activity nodes which represents $65 \%$ of residential areas.

- Location of major cross streets and transfer points that almost $50 \%$ commercial areas.

- Density and land-use patterns (Hess, Paul \& Moudon, Anne \& Logsdon, Miles., 2001) stated the land use types served as proxies from trip origins to destinations:

- Land uses encourage commuting by looking at the influence of retail activities (Dargay, Joyce \& Hanly, Mark., 2003).

- Destinations of retail and other commercial within close proximity to residential areas (Susan Handy, Patricia Mokhtarian, Theodore Buehler and Xinyu Cao, 2004)

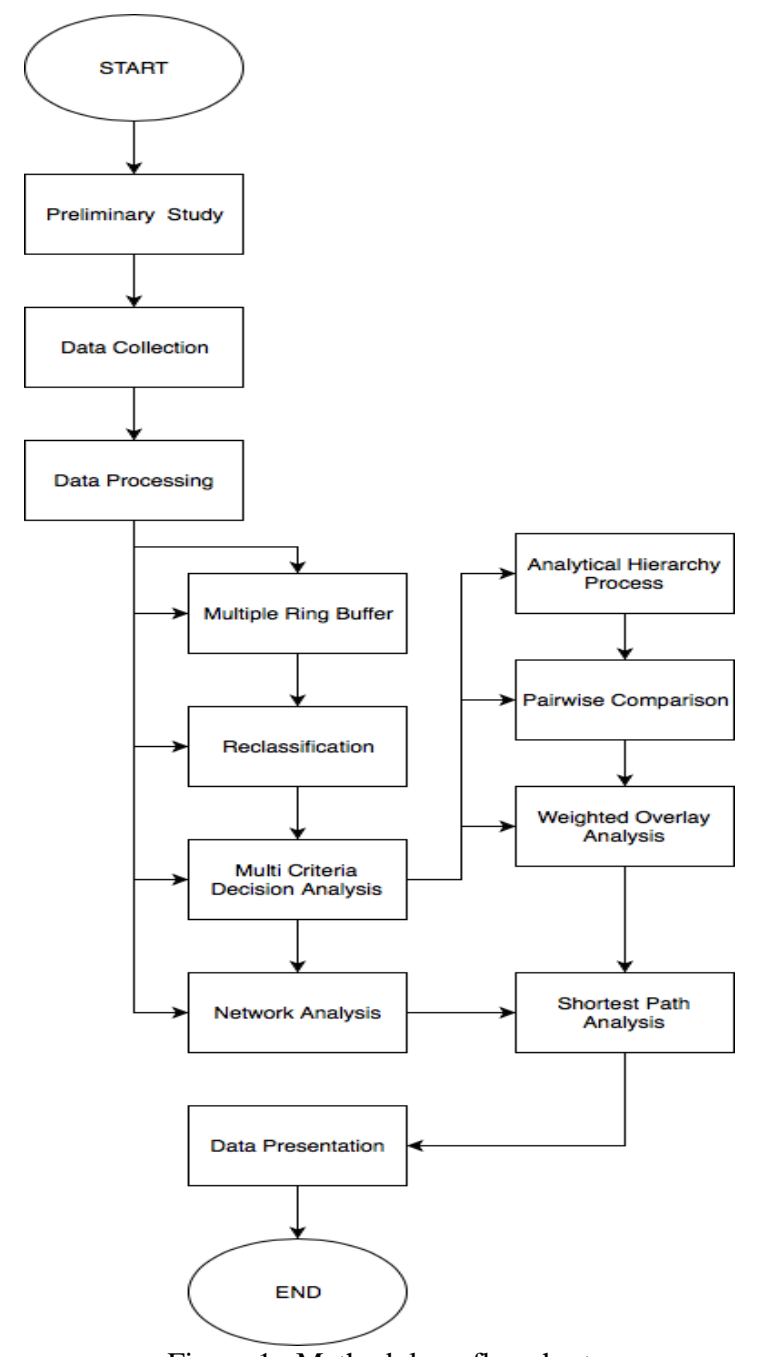

Figure 1 Methodology flowchart

Benn (1995) has defined ten criteria for route design standards, which can be considered, are as follows:

- Network connectivity is the physical relationship of a new routing to the existing route system already in place at the agency and selected as a primary design element by 9 percent. Onn, Chiu \& Karim, Mohamed \& Yusoff, Sumiani. (2014) has defined that populations lived within 400 meters of a bus route.

- Population density represents the number of people residing per square kilometers. It is the best representation of the potential, in terms of daily trips, at the point of origin and this parameter selected by 74 percent.

- Proximity to residences is to get as close as possible to a rider's residence without unnecessarily delaying or detouring other riders and selected as primary parameter by 19 percent.

- Proximity to non-residential trip generators is to get as close as possible to a rider's non-home destination without unnecessarily delaying or detouring other riders within major commercial areas (Mistretta, 2009) and selected as primary parameter by 18 percent.

- Bus stop spacing is the bus stops with easy walking distances and it follows that the fewer the stops, the greater the number of people who will walk. This parameter selected as primary data over 85 percent. According to Roberts (2010), maximum acceptable and desirable walking distances 
A detailed description of these effective criteria is given below that have been selected according to the guide direction and legislations of Iran Department of the Environment and municipality (Mahini, A. and Abedian, S, 2014).

- Proximity to Residential areas: Road construction has diverse effects on the populated centers such as reduction of travel time and based on expert judgement, suggested that the best road pathway was in distance $700 \mathrm{~m}$ and 3,000 $\mathrm{m}$ from residential areas (Kim et al. 2011).

- Proximity to Road Network: The location of proposed roads in an optimal distance from the existing roads were decided to be approximately within $400 \mathrm{~m}$ (Mahini, A. and Abedian, S, 2014).

- Mahini, A. and Abedian, S, (2014) also stated that the proximity to roadside facilities is where the construction rules do not allow that road is constructed within $100 \mathrm{~m}$ of roadside facilities. However, it is desirable that a road be as close to road facilities as possible.

- Land-use: Land-use map contains different types of land use each of them with a different suitability for road routing. The identified uses in the study area are consisted of residential areas, commercial areas, working areas, schools, hospitals and tourist attractions (Mahini, A. and Abedian, S, 2014).

Based on the brief discussion of each parameter used for route design, it is evident that these parameters can be applied in determining and establishing the route for the BRT, only few are selected for multi criteria decision analysis purpose, which are:

Population Density: It is the best representation of the potential, in terms of daily trips, at the point of origin. This data represents the number of people residing per square kilometers.

Existing Route: The bus rapid transit (BRT) lanes are typically built along existing routes that has high population densities, so also does ridership (Cervero, 2013).

Bus Stops: Bus stops are points of pick up and drop off of passengers and the bus stops with easy walking distances attracts greater number of people willing to walk and boarded the buses.

Proximity to Residences: To get as close as possible to commuters' residence within short walking distance, without unnecessarily delaying or detouring other riders and most origin of ridership is from residential areas.

Proximity to non-Residences: To get as close as possible to a rider's non-home destination, like working areas, commercial areas, schools, or retail areas which within walking distance.

Landuse: Land use patterns, which used as to determine the trip from origin to destinations (Roberts, 2010).

\subsection{Data Collection}

Data collection involves two phases, which are primary data and secondary data. Primary data will be collected from current practices with focus on: most recent routes and evaluation criteria for route design (Benn, 1995), with the expert judgement of related agencies in bus transit services which is Iskandar Regional Development Authority (IRDA), while secondary data consists of population density of study area which can be extract from website of Department of Statistics Malaysia and directions of buses and bus stops can be collected from the website of bus transit which is Pengangkutan Awam Johor (PAJ), Johor Bahru.

Figure 2 shows the process of data collection based on selected criteria for analysis that will be used to generate route suggestion for BRT.

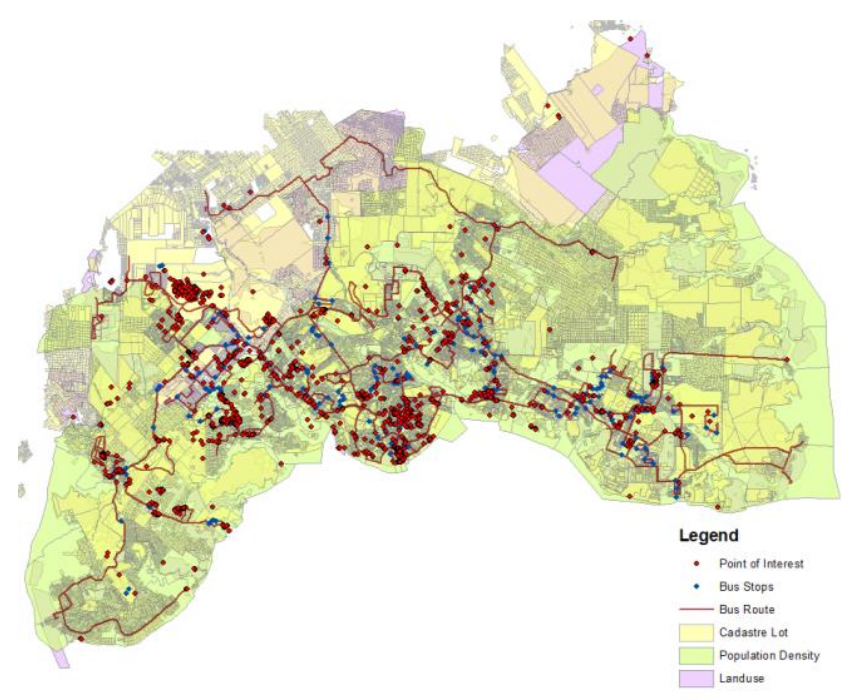

Figure 2 Collected data within study area

\subsection{Data Processing}

Data extraction transformed raw data into format that can be used in ArcGIS software. In this study, data pre-processing has been carried out on land use in order to determine which route can be utilized for new bus routes. However, it is compulsory to create database for all the data collected during data collection phase in order to tabulate the data collected during data collection stage.

Apart from the roads, commercial areas and government offices have also been putting in to consideration due to the high number of commuters relaying on buses in and around the areas. Using multi criteria decision analysis best routes for buses can be designed which will take in to consideration the high population density around Johor Bahru. This information can be useful for crucial decision-making as it represents the population growth and road congestion of study area during peak hours. The process of structuring new bus routes can be carried out, which by extracting the value of population density.

\subsubsection{Multi Criteria Decision Analysis}

Multi-criteria decision analysis is a process that combines and transforms input of geographical data into a resultant decision. Geographical information can be defined as geo-referenced data that has been processed into a form meaningful to the recipient. The data in geographical information systems are most commonly organized by separate sets of data, referred to as a map layer. In allocating the bus routes, it is crucial to define the criteria for selecting the optimal bus routes. It is important consideration as it can eliminate all road network that falls outside the region of Iskandar Malaysia, Johor Bahru. After defining the criteria, spatial data collection and multi criteria analysis begins in order to map the result of the efficient routes for BRT. 
In order to generates priorities, Kartasasmita (2015) stated that it should be organized in concise manner as follows:

- $\quad$ Define the problem.

- Structure the decision hierarchy from the top with the goal of the decision.

- The objectives from a broad perspective

- Construct a set of pairwise comparison matrices. Each element in an upper level is used to compare with the elements in the level that is below with respect to it.

- Use the priorities obtained from the comparisons to weigh the priorities in the level below. Apply to Do each element. Then for each element in the level below, just add its weighed values and the total value. Continue this process of weighing and adding until the final priorities of the alternatives are obtained.

\section{a) Analytic Hierarchy Process (AHP)}

The Analytic Hierarchy Process (AHP) is an approach to multiattribute decision making based on the concept of pairwise comparisons that is capable of analyzing a complex situation by breaking down the problem in to parts and organizing them following a hierarchy, by assigning numerical values to subjective judgments on the relative importance of each variable and finally synthesizing the judgments to obtain the global priority of the actions (Saaty, 1980).

Analytic Hierarchy Process (AHP) is used to determine the weights of the criteria based on scores of relative importance for each criterion in pair-wise comparisons. Pairwise comparisons are the basic calculations employed in the AHP procedure which simplifies the decision making that involves three steps (Malczewski, 2010): 1) development of a comparison matrix at each level of the hierarchy; b) weights computations for each element of the hierarchy; and c) estimation of consistency ratio (CR). Table 1 shows the intensity of importance with definitions to define each scale.

Table 1 Scale for Pairwise Comparison

\begin{tabular}{cc}
\hline $\begin{array}{c}\text { Intensity of } \\
\text { Importance }\end{array}$ & Definition \\
\hline 1 & Equal Importance \\
2 & Equal to Moderate Importance \\
3 & Moderate Importance \\
4 & Moderate to Strong Importance \\
5 & Strong Importance \\
6 & Strong to Very Strong Importance \\
7 & Very Strong Importance \\
8 & Very to extremely strong Importance \\
9 & Extreme importance \\
\hline
\end{tabular}

Source: Saaty (1980)

\section{b) Pairwise Comparison Method}

Pairwise comparison method involves time consuming computations. Fortunately computer programs can perform the calculations by using Expert Choice software packages for the pairwise comparison procedure (Expert Choice, Inc., 1993). This method involves an underlying scale with the value from 1 to 10 to rate the relative preferences for two nodes of hierarchy belonging to the same level (Malczewski, 2010).
After completing the pair-wise comparison, the consistency must be checked by making sure the value of inconsistency shown in Figure 3, is $<0.10$, the reasonable ratio that the level of consistency in the pairwise comparisons, if more than 0.10 the pairwise comparison must be reassessed.

Synthesis with respect to: Goal: To rank the parameters

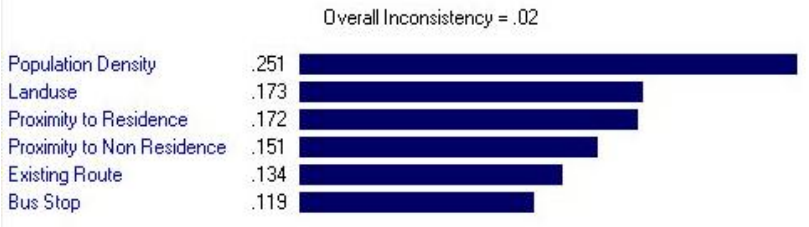

Figure 3 Consistency value of Pairwise Comparison

\section{c) Weighted Overlay}

Weighted overlay is a tool that overlay the criteria for each parameter based on their weight and rank according to their importance level. Weighted Overlay analysis as shown in Figure 4, was used to perform an overlay analysis for all parameters to allocate the potential area for BRT routing. The Weighted Overlay use scale rank to define the importance of the criteria.

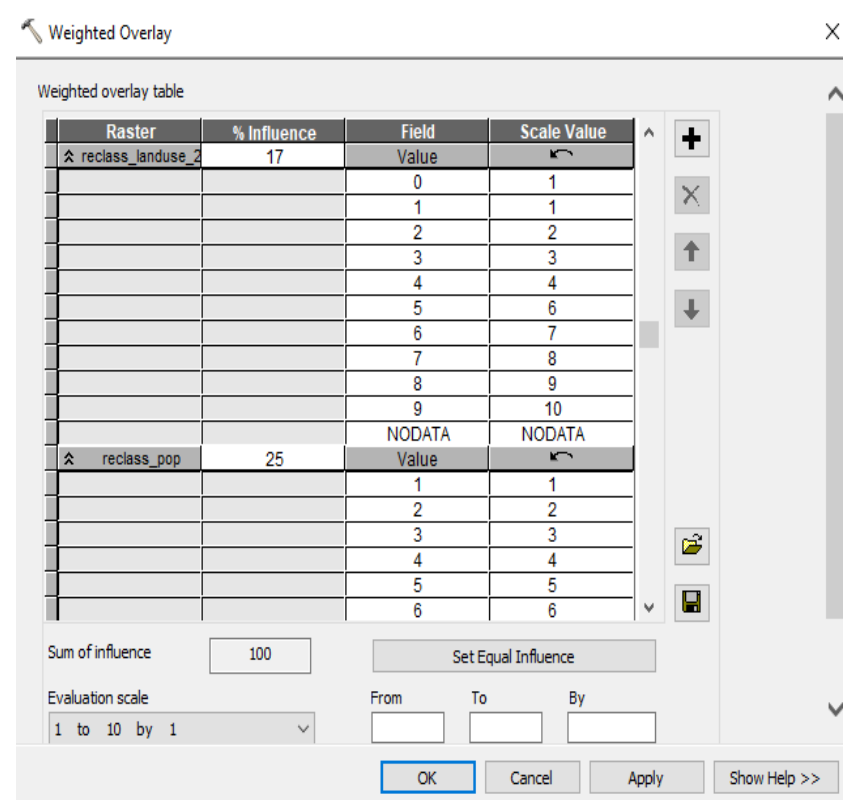

Figure 4 Weighted Overlay tool

The result of weight parameter obtained from AHP will be used to generate the potential area that suitable for producing BRT route. In this tool, it is compulsory to use raster data format that has been reclassified based on ranking. Using the value of weight for each parameter obtained from pairwise comparison method, fill in the influence field. Figure 5 shows the potential area of Extreme Importance generated by Weighted Overlay tool. The Extreme Importance area is depicted in green colour, while, Equal Importance area is represented in yellow colour and blue colour is the Moderate Importance area. 


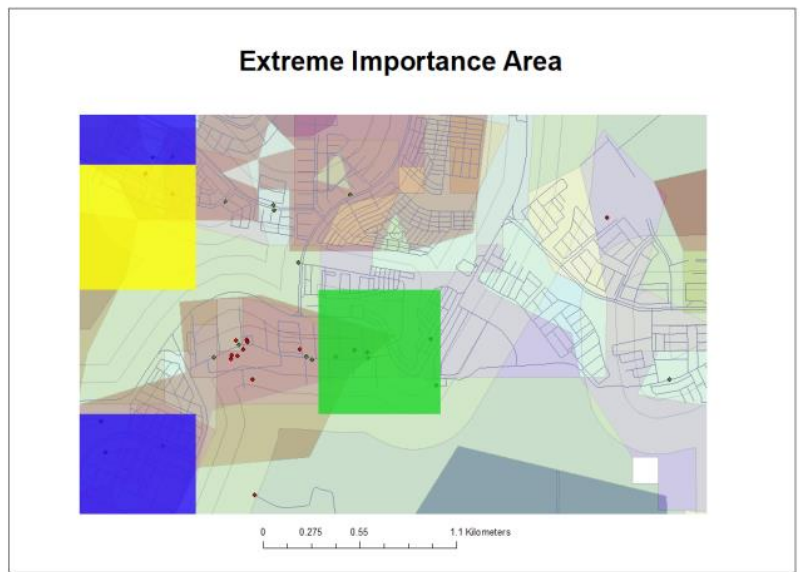

Figure 5 MCDA Result for Extreme Importance Area

\subsubsection{Network Analysis}

Network analysis is one of the components in MCDA, which has the ability to identify the most optimum routes and to generate directions for the BRT. This analysis will be performed to overlay the road network on top of the result of multi criteria decision analysis. This network analysis is used to define the routes that is capable of reaching as many point of interest as possible, that can be populated using multi criteria decision analysis.

One of the objectives of this research is to find the shortest, fastest and effective routes using network analysis, capable of conveying commuters from one destination to the other in both urban and rural areas. According to Roberts (2010), the shortest routes will provide an opportunity for late comers to reach their destination in a shortest possible time and this is one advantage of rapid transit bus, that has it is own personal lane, especially in a highly populated environment

At this phase, road network data and base map of study area have been prepared as seen in Figure 6. Base map can be accessed from ArcGIS Online Services and this requires internet access throughout the processing.

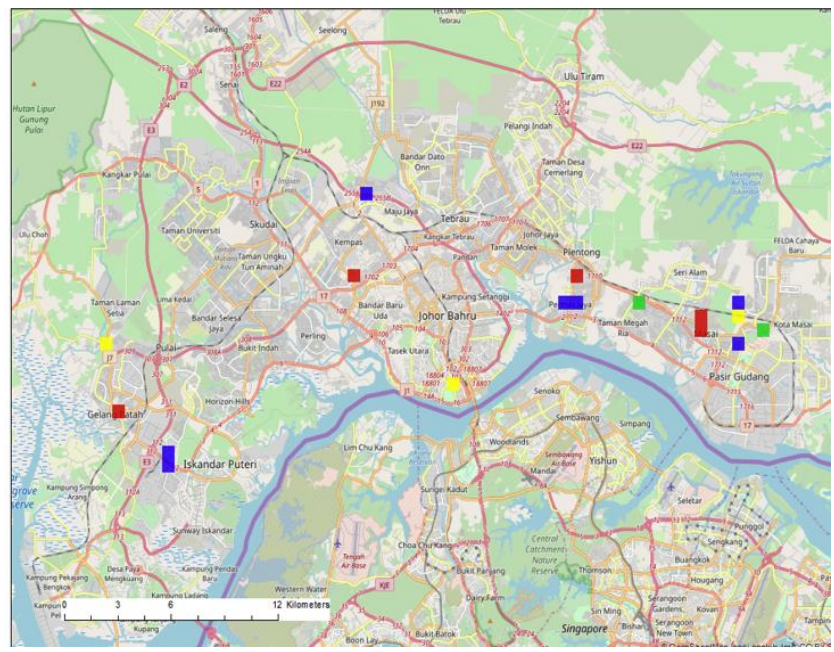

Figure 6 Data preparation for network analysis

\section{a) Geo Database}

A personal Geo-database has been created using ArcGIS that can store, query, and manage both spatial and non-spatial data.
It will contain the result of multi criteria decision analysis (MCDA), road network, existing routes of current bus services, and main road. Each layer will be in vector form because it has higher geographic accuracy and not dependent on grid size like raster data.

b) Network Topology

Topology tracks is required to validate features using the topology command that analyzes the edited areas and evaluates the rules. If the rule is violated, it will be expressed as topology errors. The topology error feature is created and can be corrected by applying some topology rules such as ensuring that there are no dangles in the road network and the roads do not intersect or overlap with themselves or mark them as exceptions to the rule.

\section{c) Network Dataset}

After rectifying and correcting the road networks, the data has been utilised in building the network dataset for network analysis. The creation of network dataset $\mathrm{s}$ crucial in network analysis and it is created after correcting the topological errors. The line feature class will represent the road network and must be stored in a feature dataset. The network dataset is well suited to model the transportation network.

\section{RESULTS AND DISCUSSION}

The results of the analysis show an urgent need to expands public transport system in Johor Bahru due to the rising population and land used pattern and hence, BRT will be suitable due to it is efficiency, reliability and affordability. The result can therefore be classified in to four categories, which are Equal Importance, Moderate Importance, Strong Importance as well as Extreme Importance (See Figure 9). Using weightage overlay tool, it shows that the result from Equal Importance to Extreme Importance were generated using AHP, that has employed Pairwise Comparison Method. However, 'Equal Importance' area has potential because it consists of optimum criteria compared to other area which priorities commercial areas and health areas within $100 \mathrm{~m}$ to $200 \mathrm{~m}$ of buffer for bus stops and nonresidential areas but not within high-populated area as 'Extreme Importance' area, however, two elements contribute equally to the objective.

This analysis applied multiple ring buffer on vector data of point features which are:

- The optimum points have $100 \mathrm{~m}$ buffer zone (Dedemen, 2013) and (Translink, 2005) stated that for the elderly and mobility impaired, there should be not more than $100 \mathrm{~m}$ between development areas and the bus stops.

- The majority of residents have no more than $200 \mathrm{~m}$ to walk between their homes and the bus stop (Translink, 2005).

- No resident has to walk more than $400 \mathrm{~m}$ from their home to the bus stop (Translink, 2005).

Based on the literature, multiple ring buffer is used to restrict the buffer up to $100 \mathrm{~m}, 200 \mathrm{~m}$, and 400m, as shown in Figure 7.

Reclassification is a tool to reclassify the vector data into raster classes, Figure 8 shows the result of the analysis after rasterization process with resulting pixel up to $400 \mathrm{~m}$ distance value. Roberts (2010) stated that the actual distance people are willing to walk varies depending on the proximity between their 
settlements or working environment to the pickup points. Commuters can walk to a nearby point of departure not more than $1 \mathrm{~km}$ or at least 0.1 to $0.4 \mathrm{~km}$ or distance not more than 10minutes from their destinations. In higher-density or highactivity areas, expectations are usually for shorter walks (Roberts, 2010).

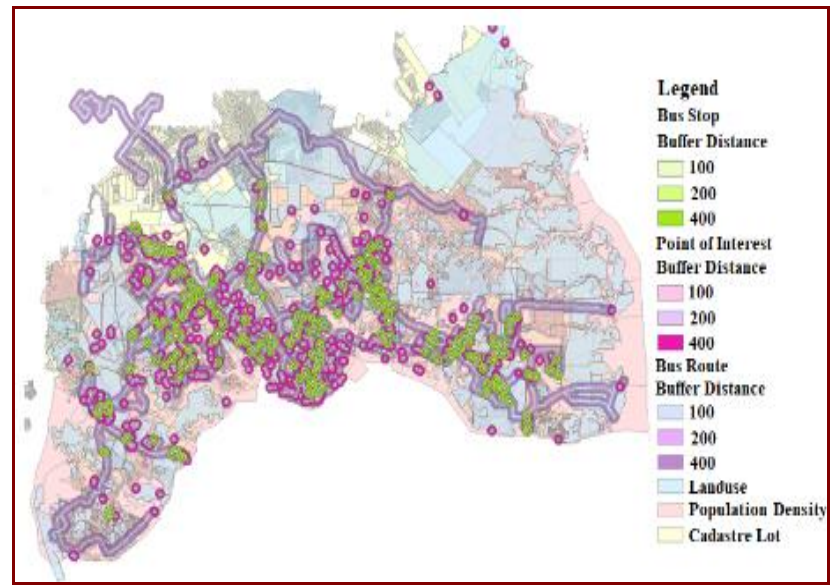

Figure 7 Multiple Ring Buffer performed on vector features

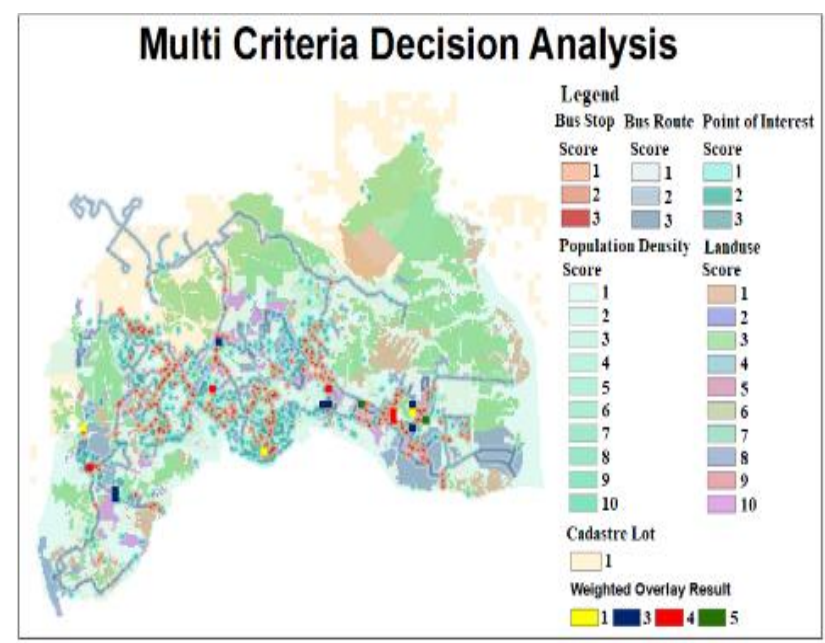

Figure 8 Reclassified Data based on Ranking

According to Figure 9, the green color represents the 'Extreme Importance' area meanwhile 'Strong Importance' areas were represented by the red color. Additionally, 'Moderate Importance' areas are represented by blue color while yellow color depicts the 'Equal Importance' area. Since the generated result of multi criteria decision analysis were classified in to four different classes, the fundamental scale of Pairwise Comparison method for the intensity of importance is used. The network connectivity of those areas are generated with restriction of main roads or highways only.

Figure 10 shows the shortest distance of moderate importance route, which connects all areas of 'Moderate Importance'. The result obtained from multi criteria decision analysis (MCDA) were used to proceed with the network analysis in order to generate the bus route for BRT. The route is produced using network analysis, which restricted only on main roads because dedicated bus lanes are typically applied on major routes and highways or expressways where existing travel lanes are feasible (NACTO, 2007).

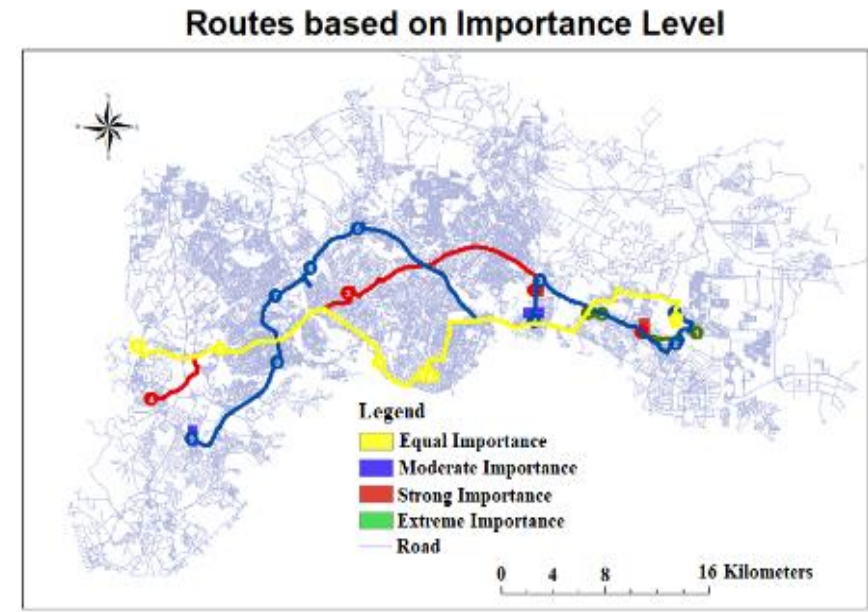

Figure 9 Routes based on MCDA Result

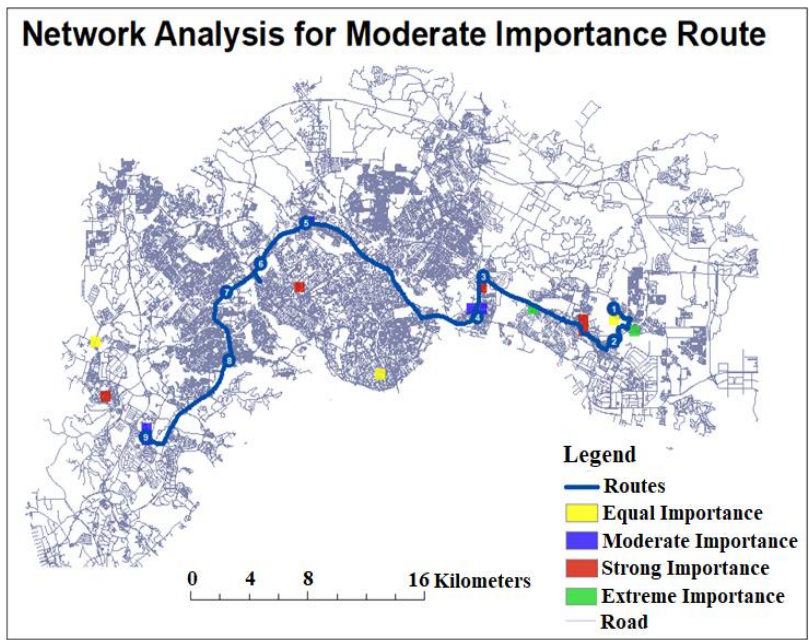

Figure 10 Moderate Importance Route map

Figure 11 shows the direction starting from the first location to the other using only main roads or highways only.

\begin{tabular}{|c|c|c|c|c|}
\hline f Direct & ns (Route 3) & & $\square$ & \\
\hline$[-]$ Rou & e: Graphic Pick 1 - Graphic Pick 6 & $25 \mathrm{~km}$ & Map & \\
\hline 1: & Start at Graphic Pick 1 & & Map & \\
\hline 2: & Go northwest on Jalan Dato Dalam & $57 \mathrm{~m}$ & Map & \\
\hline 3: & Turn left & $182 \mathrm{~m}$ & Map & \\
\hline 4: & Turn right on Jalan Ayer Molek & $198 \mathrm{~m}$ & Map & \\
\hline 5: & Turn right on Jalan Gertak Merah & $120 \mathrm{~m}$ & Map & \\
\hline 6: & Arrive at Graphic Pick 2, on the right & & Map & \\
\hline Z: & Depart Graphic Pick 2 & & & \\
\hline 8: & Go back southwest on Jalan Gertak Merah & $120 \mathrm{~m}$ & Map & \\
\hline 9: & Turn right & $28 \mathrm{~m}$ & Map & \\
\hline 10: & Continue on Jalan Yahya Awal & $308 \mathrm{~m}$ & Map & \\
\hline 11: & Turn left on Jalan Mahmoodiah & $335 \mathrm{~m}$ & Map & \\
\hline 12: & Arrive at Graphic Pick 3, on the left & & Map & \\
\hline 13: & Depart Graphic Pick 3 & & & \\
\hline 14: & Continue southwest on Jalan Mahmoodiah & $861 \mathrm{~m}$ & Map & \\
\hline 15: & Turn left on Jalan Lingkaran Dalam & $203 \mathrm{~m}$ & Map & \\
\hline 16: & Bear right & $17 \mathrm{~m}$ & Map & \\
\hline 17: & Bear left on Johor Bahru Inner Ring Road & $62 \mathrm{~m}$ & Map & $\checkmark$ \\
\hline Options & Print Preview... & Print & Close & \\
\hline
\end{tabular}

Figure 11 Direction of Bus Route

Validation of the bus route map based on the potential area was performed using the existing bus routes of the study area. The BRT lanes are typically built along existing routes where high population densities exist, so also does ridership (Cervero, 2013). The existing bus routes consist of residential roads, 
which are not suitable area for building BRT lanes. Research indicates that a 12-foot shoulder is desirable for BRT operations for uninterrupted-flow, where a 10 -foot shoulder should be the minimum for BRT operations (Ki elson \& Associates, Inc., 2013).

Based on statistical data for 'Extreme Importance' potential areas consist of optimum criteria for each parameter, which shows high-populated area within range of 100 meters of buffer and has the highest score of land use pattern. From the validation process, it can be concluded that the results for this study are acceptable and reasonable.

Figure 12 is the map of BRT route that connects all the areas which has been generated using multi criteria decision analysis. The new suggested routes generated connecting 4 flagship zones of Eastern Gate Development, Western Gate Development, and Senai-Skudai that centralised from JB city centre. This is due to the fact that JB city centre serves as a terminal where most of the commercial activities are taking place within the city.

\section{CONCLUSION}

In this paper, multi criteria decision analysis and network analysis provide an opportunity to determine the much needed parameters for the actualization of the BRT routes based on the existing routes in Johor Bahru. Bus rapid transit will bring rapid development, travel efficiency and reliability which will cut across all the town and villages in Johor Bahru.

The results of the analysis also show efficiency and reliability of using multi criteria decision analysis and network analysis in suggesting new routes for the establishment of any form of public transportations that will succeed in solving issues related to traveller's grievances pertaining delay in reaching their desired destinations. However, the result is under review, and there are a number of suggestions that need further verification, such as:

- More studies of how various parameter and network data can be succesfully obtained

- More studies of how to prove the multi criteria analysis statistically using the Kolmogorov-Smirnov (K-S) test (Justel et al., 1997).

\section{ACKNOWLEDGEMENT}

I would like to take this opportunity to thank all the agencies, which are Pengangkutan Awam Johor (PAJ) and Iskandar Regional Development Authority (IRDA), for their support in providing the data and guidance. I wish to express my gratitude and dedicate this small achievement to my parents.

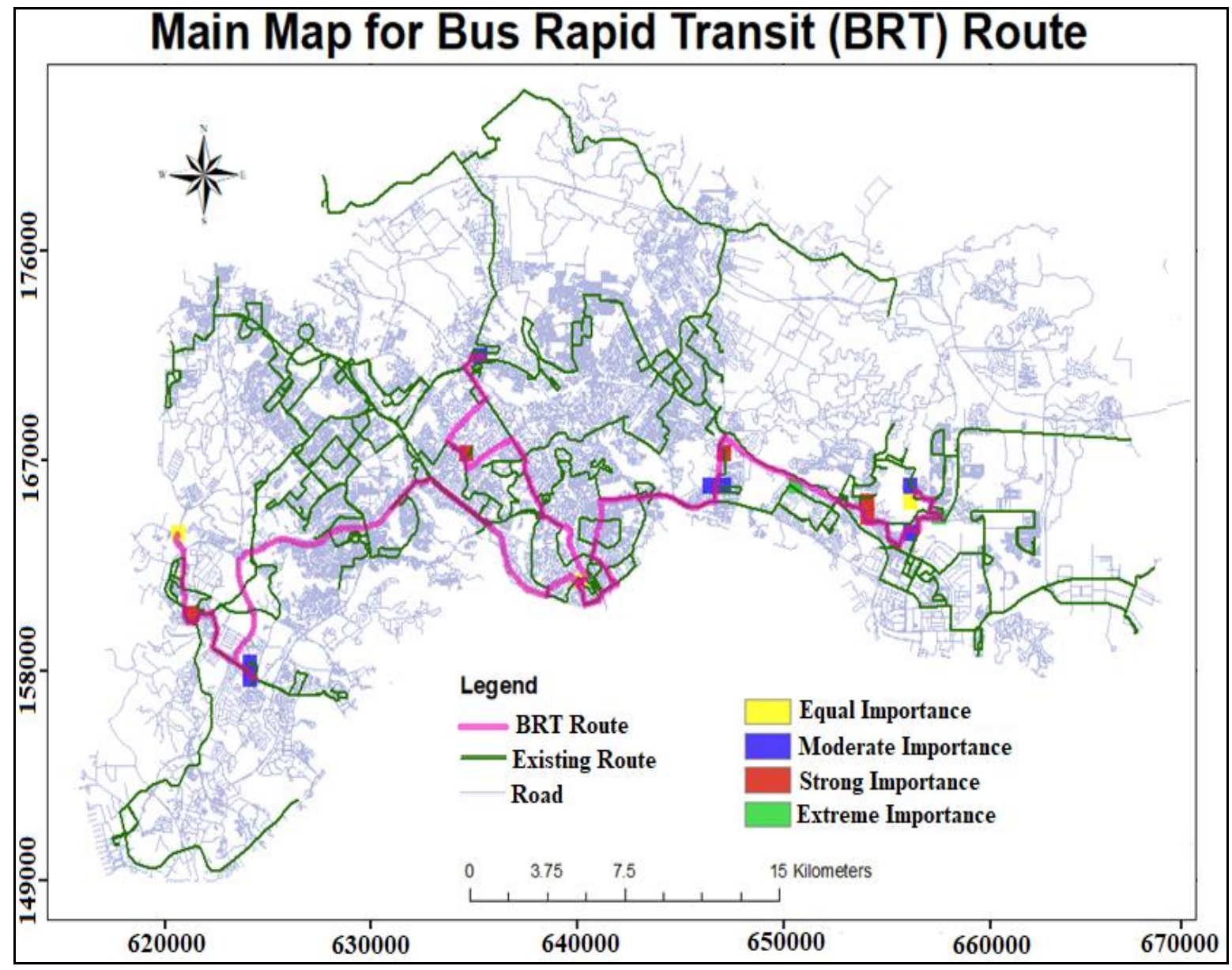

Figure 12 Bus Rapid Transit (BRT) Route map 


\section{REFERENCES}

Akay, A. E., Wing, M. G., Sivrikaya, F., \& Sakar, D. (2011). A GIS-based decision support system for determining the shortest and safest route to forest fires: A case study in Mediterranean Region of Turkey. Environmental Monitoring and Assessment, 184(3), 1391-1407. doi:10.1007/s10661-011-2049-z

Azizan, M., Ibrahim, F., Ismail, R., \& N. I. (2016). Implementation of Systematic Public Transportation in Malaysia: Development of Bus Rapid Transit. International Journal of Chemical, Environmental \& Biological Sciences (IJCEBS) Volume 4, Issue 2 (2016) ISSN 2320-4087, 121-123.

Benn, H. P. (1995). Bus route evaluation standards (No. Project SA-1).

Cervero, R. (2013). Bus rapid transit (BRT): An efficient and competitive mode of public transport.

Cain, A., \& Flynn, J. (2013). Examining the ridership attraction potential of bus rapid transit: A quantitative analysis of image and perception. Journal of public transportation, 16(4), 4. doi: http://doi.org/10.5038/2375-0901.16.4.4

Cervero, R., \& Kang, C. D. (2011). Bus rapid transit impacts on land uses and land values in Seoul, Korea. Transport Policy, $18(1), 102-116$

Chien, S. I. J., Dimitrijevic, B. V., \& Spasovic, L. N. (2003). Optimization of bus route planning in urban commuter networks. Journal of Public Transportation, 6(1), 4.

Chuen, O. C., Karim, M. R., \& Yusoff, S. (2014). Mode choice between private and public transport in Klang Valley, Malaysia. The Scientific World Journal, 2014.

Dargay, J. M., \& Hanly, M. (2003, October). The impact of land use patterns on travel behaviour. In European Transport Conference, Strasbourg, France.

Dedemen, Y. (2013). A multi-criteria decision analysis approach to GIS-based route selection for overhead power transmission lines. Middle East Technical University.

Expert Choice, Inc. (1993). Expert Choice version 8: user manual. McLean, VA: Decision Support Software, Inc.

Farkas, A. (2009). An Intelligent GIS-Based Route/Site Selection Plan of a Metro-Rail Network. In Towards Intelligent Engineering and Information Technology (pp. 719-734). Springer, Berlin, Heidelberg.

Farkas, A. (2009). Route/Site Selection of Urban Transportation Facilities: An Integrated GIS/MCDM Approach. Proceeding of MEB 2009-7th International Conference on Management, Enterprise and Benchmarking, June 5-6 2009, Budapest, Hungary.

Fischer, M. M. (2006). Spatial analysis and geocomputation: selected essays. Springer Science \& Business Media.

Gonçalves, A. B. (2010). An extension of GIS-based least-cost path modelling to the location of wide paths. International Journal of Geographical Information Science, 24(7), 983-996. DOI: $10.1080 / 13658810903401016$
Goodwin, P. (1992). A Review of New Demand Elasticities with Special Reference to Short and Long Run Effects of Price Changes. Journal of Transport Economics and Policy, 26(2), 155-169. Retrieved from http://www.jstor.org/stable/20052977 Guide, U. B. D. (2011). National Association of City Transportation Officials. New York, 8.

Hook, W. (2006). Urban transportation and the millennium development goals. Global Urban Development, 2(1), 1-9.

Hensher, D. A., \& Golob, T. F. (2008). Bus rapid transit systems: a comparative assessment. Transportation, 35(4), 501518

Imran, M. (2009). Public transport in Pakistan: a critical overview. Journal of Public Transportation, 12(2), 4. doi: http://doi.org/10.5038/2375-0901.12.2.4

Justel, A., Peña, D., \& Zamar, R. (1997). A multivariate Kolmogorov-Smirnov test of goodness of fit. Statistics \& Probability Letters, 35(3), 251-259.

Kartasasmita, F. I., Sofyan, A., Frazila, B., \& Bayu, I. M. (2015). Analytic Hierarchy Process for the Evaluation of Transport Policies in Bandung City

Keenan, P. (2008). Modelling vehicle routing in GIS. Operational Research, 8(3), 201. doi: https://doi.org/10.1007/s12351-008-0021-7

Ki elson \& Associates, Inc. (2013) Florida Department of Transportation: TYPICAL SECTIONS FOR EXCLUSIVE TRANSIT RUNNING WAYS

Kementerian Pengangkutan Malaysia: National Key Result Area (NKRA)

Kicinski, Marcin \& Solecka, Katarzyna. (2018). Application of MCDA/MCDM methods for an integrated urban public transportation system - case study, city of Cracow. Archives of Transport. 46. 71-84. 10.5604/01.3001.0012.2107.

Kiciński, M., \& Solecka, K. (2018). Application of MCDA/MCDM methods for an integrated urban public transportation system-case study, city of Cracow. Archives of Transport, 46.

Lisco, T. E. (1968). Value of commuters travel time-a study in urban transportation (No. 234).

Lutz, H. (2014). Transportation Solutions for Rural Seniors Levinson, H. S., Zimmerman, S., Clinger, J., \& Rutherford, G. S. (2002). Bus rapid transit: An overview. Journal of Public Transportation, 5(2), 1.

Malczewski, J. (2006). GIS-based multicriteria decision analysis: a survey of the literature. International journal of geographical information science, 20(7), 703-726. DOI: 10.1080/13658810600661508

Mitchell Hess, P., Vernez Moudon, A., \& Logsdon, M. G. (2001). Measuring land use patterns for transportation research. Transportation Research Record, 1780(1), 17-24.

Mistretta, M., Goodwill, J. A., Gregg, R., \& DeAnnuntis, C. (2009). Best practices in transit service planning. 
Mahini, A., \& Abedian, S. (2014). Routing of road network through least cost pathway algorithm to minimize impacts on environment. Journal of the Indian Society of Remote Sensing, 42(3), 517-527. doi: https://doi.org/10.1007/s12524-013-0351-7 Mosaberpanah, M. A., \& Khales, S. D. (2012, November). The role of transportation in sustainable development. In International Conference on Sustainable Design, Engineering and Construction (ICSDEC) (pp. 441-448).

Malczewski, J. (2010). Multiple criteria decision analysis and geographic information systems. In Trends in multiple criteria decision analysis (pp. 369-395). Springer, Boston, MA.

Pojani, D., \& Stead, D. (2015). Sustainable urban transport in the developing world: beyond megacities. Sustainability, 7(6), 7784-7805.

Rikalovic, A., Cosic, I., \& Lazarevic, D. (2014). GIS Based Multi-criteria Analysis for Industrial Site Selection. Procedia Engineering, 69, 1054-1063. doi:10.1016/j.proeng.2014.03.090 Roberts, D. (2010). American Public Transportation Association: Bus Rapid Transit Service Design. 125-132.

Saaty, T.L. (1980) The Analytic Hierarchy Process, McGraw Hill, New York.

Thomas, E. (2001). Presentation at institute of transportation engineers meeting. Chicago (August).

Handy, S., Mokhtarian, P., Buehler, T., \& Cao, X. (2004). Residential location choice and travel behavior: Implications for air quality. Prepared for the California Department of Transportation, Davis, CA.

Wang, Q., \& Zheng, H. (2006, January). Route and spectrum selection in dynamic spectrum networks. In IEEE Consumer Communications and Networking Conference (CNCC) (pp. 342-346).

Wardman, M. (2004). Public transport values of time. Transport policy, 11(4), 363-377.

Wright, L., \& Fjellstrom, K. (2003). Sustainable Transport: A Sourcebook for Policy-makers in Developing Cities. Module 3a: Mass Transit Options.

Wright, L. (2003). Module 3b: Bus Rapid Transit. Sustainable Transport: A Sourcebook for Policy-makers in Developing Cities, 1-41.

Translink (2005). Bus Stop Design Guide

Transport, S. (2004). A Sourcebook for Policy-makers in Developing Cities. Module 2a. Land Use Planning and Urban Transport.

Zhou, Y., \& Liu, M. (2011, August). An Intelligent System for Emergency Traffic Routing. In International Conference on Applied Informatics and Communication (pp. 429-436). Springer, Berlin, Heidelberg. 